\title{
Desempenho da soja em sucessão ao consórcio de milho segunda safra com diferentes densidades de Crotalaria spectabilis
}

\author{
Edison Ulisses RAMOS JUNIOR ${ }^{1}$, Eduardo Megier de Ramos², Luana Manoela Konzen², \\ Valéria de Oliveira Faleiro ${ }^{3}$, Alexandre Ferreira da Silva ${ }^{4}$, Flávio Dessaune Tardin ${ }^{4}$. \\ ${ }^{1}$ Embrapa Soja, Londrina, PR, Brasil. \\ ${ }^{2}$ Universidade Federal de Mato Grosso, Sinop, MT, Brasil. \\ ${ }^{3}$ Embrapa Agrossilvipastoril, Sinop, MT, Brasil. \\ ${ }^{4}$ Embrapa Milho e Sorgo, Sete Lagoas, MG, Brasil. \\ *E-mail: edison.ramos@embrapa.br
}

Recebido em fevereiro/2019; Aceito em agosto/2019.

RESUMO: A demanda crescente por alimentos, associada à necessidade de preservação ambiental, e a disponibilidade limitada de terras para a expansão da área cultivada, tem demandado desenvolvimento contínuo de tecnologias que resultem no aumento da produtividade de grãos, na racionalização do uso de insumos, dos recursos ambientais e dos meios de produção. O presente trabalho teve como objetivo avaliar o desempenho da soja (Glycine max (L.) Merrill) semeada em sucessão ao consórcio de milho (Zea mays L.) segunda safra com diferentes densidades de Crotalaria spectabilis. O experimento foi semeado em 15 de fevereiro de 2016, em uma área experimental da Embrapa Agrossilvipastoril, na cidade de Sinop/MT. O delineamento utilizado foi de blocos ao acaso, com quatro repetições. Cada parcela apresentava 11 linhas com $0,45 \mathrm{~cm}$ de espaçamento entre si e 10 metros de comprimento, sendo considerada, como área útil, as três linhas centrais. Os tratamentos foram constituídos de 4 densidades da $C$. spectabilis, sendo 10,20,30 e $40 \mathrm{~kg}$ de sementes por ha, além da testemunha, com milho solteiro. A semeadura da soja foi realizada em outubro de 2016, sob as parcelas colhidas do consórcio de milho com crotalária. Ao final do ciclo, coletou-se 10 plantas da área útil de cada parcela, para que fossem avaliados os componentes de produção e produtividade da cultura. Observou-se que a crotalária não causou redução na produtividade de grãos do milho, porém em apenas um ciclo de consórcio, não permitiu que se obtivessem incrementos na produtividade de grãos da soja.

Palavras-chave: diversificação de culturas; consórcio milho-crotalária; produtividade de grãos.

\section{Performance of soybean in succession to maize second crop intercropped with different sowing density with Crotalaria spectabilis}

\begin{abstract}
The growing demand for food, associated with the need for environmental preservation, and the limited availability of land for the expansion of cultivated area, has demanded continuous development of technologies that result in increased grain productivity, rationalization of input use, environment resources and the means of production. The objective of this work was to evaluate the performance of soybean (Glycine max (L.) Merrill) in succession to the intercropped of maize (Zea mays) second crop with different densities of Crotalaria spectabilis. The experiment was sowing on February 15, 2016, in an experimental area of Embrapa Agrossilvopastoral, in the city of Sinop/MT. The experimental design was a randomized complete block, with four replications. Each plot had 11 lines with $0.45 \mathrm{~cm}$ of spacing and 10 meters of length, being considered as useful area, the three central plots. The treatments consisted of 4 densities of $C$. spectabilis, being 10, 20, 30 and $40 \mathrm{~kg}$ of seeds per hectare, besides the control with the single maize. The sowing of the soybean was carried out in October 2016, under the plots harvested from the maize intercropped with the Crotalaria, where the cultivar M 8210IPRO was used and at the end of the cycle 10 plants of the useful area of each plot were collected, so that Production components. With the results obtained, it was possible to observe that the crotalaria did not cause a reduction in corn grain yield, but in only one consortium cycle, it did not allow the increase of grain yield of the soybean. Therefore, the continuity of the work must be carried out in order to be able to obtain increases in soybean production in succession, and also to evaluate the best $C$. spectabilis density to be used in intercropping. Keywords: crop diversification; maize-crotalaria intercrop; grain yield.
\end{abstract}

\section{INTRODUÇÃO}

A demanda crescente por alimentos, associada à necessidade de preservação ambiental, e a disponibilidade limitada de terras para a expansão da área cultivada, tem demandado desenvolvimento contínuo de tecnologias que resultem no aumento da produtividade de grãos, na racionalização do uso de insumos, dos recursos ambientais e dos meios de produção. Segundo Macedo (2009), o monocultivo e as práticas culturais inadequadas têm causado perda de produtividade, ocorrência de pragas e doenças, e degradação do solo e dos recursos naturais. O manejo inadequado do solo por meio das atividades agropecuárias pode, com o tempo, trazer graves consequências, exaurindo suas reservas orgânicas e minerais, transformando solos com 
grande potencial de produção em solos de baixa fertilidade (DUARTE et al., 2014).

Adubação verde é técnica que consiste na utilização de certas espécies de plantas que, após atingirem seu desenvolvimento vegetativo, são incorporadas ou deixadas sobre a superfície do solo, com a finalidade de garantir o incremento de matéria orgânica que, por sua vez, aumentam a capacidade produtiva do solo, contribuindo de forma positiva para o rendimento das culturas de importância econômica (SOUZA; PIRES, 2002). Além desse benefício, Finholdt et al. (2009) acrescentam melhor aeração do solo, formação de camada de matéria orgânica que favorece os microorganismos benéficos do solo, manutenção da temperatura do solo e proteção contra erosões pela formação de palhada, além de favorecer a mobilidade de nutrientes. Quando realizada com leguminosas, como a crotalária, têm a capacidade de fixar o nitrogênio atmosférico, por meio de simbiose com bactérias do gênero Rhizobium/Bradyrhyzobium nas raízes, enriquecendo-se o solo com esse macronutriente" (MATEUS; WUTKE, 2006). Já, plantas de cobertura ou culturas de cobertura, são termos recentes utilizados para designar diferentes espécies de adubos verdes em uso para a formação da camada de palha para a cobertura do solo (CALEGARI, 2014). A cobertura de solo com camada de palha é um dos princípios do sistema plantio direto - SPD. O uso de plantas de cobertura com diferentes sistemas radiculares e relação $\mathrm{C} / \mathrm{N}$ pode favorecer tanto o controle e/ou prevenção da compactação e aumento na porosidade nas camadas superficiais e subsuperficiais do solo (COSTA et al., 2015), estimulando o crescimento radicular das culturas subsequentes (BONFIM-SILVA et al., 2012). Esses adubos verdes, ou plantas de cobertura, também são utilizados no sistema plantio direto para que seja formada a palhada, sendo importantes na ciclagem de nutrientes, que é realizada tanto pela mineralização da matéria orgânica presente no solo, como dos fertilizantes que são aplicados; porém nem todos os nutrientes são absorvidos pela cultura principal (TORRES et al., 2005).

A adoção do cultivo de adubos verdes, principalmente no verão, é pequena por parte dos agricultores, sendo afirmado que por ocupar o espaço de uma cultura comercial, o retorno econômico não é imediato (DOURADO et al., 2001). Por isso, a prática do consórcio entre o milho e as plantas de cobertura torna-se uma alternativa interessante de maneira que haja maior produção de biomassa e a cultura econômica possa ser beneficiada, mantendo ou até mesmo incrementando a produtividade (MHLANGA et al., 2016), principalmente com o consórcio de leguminosas, que irá contribuir na fixação biológica de nitrogênio (KERMAH et al., 2017).

O sucesso do sistema produtivo deve-se ao fato de que a palhada, acumulada pelas plantas de cobertura de lavouras comerciais, proporcionam um ambiente favorável à recuperação ou manutenção dos atributos físicos e químicos do solo (MENDONÇA et al., 2013), além de fornecer uma proteção das camadas superficiais do solo aos impactos das gotas de chuva (REINERT et al., 2008). Também contribuem para o aumento da produtividade da cultura subsequente (ANDREOLA et al., 2000), podendo reduzir a quantidade de adubo nitrogenado utilizado na cultura (LÁZARO et al., 2013).

O consórcio de culturas é uma prática agrícola que visa o estabelecimento de mais de uma espécie em uma mesma área. Para isto, é necessário que existam efeitos benéficos ou não prejudiciais de uma cultura sobre a outra (YADAV, 1981;
PANDEY; PENDELETON, 1986; RAMAKRISHNA et al., 1992). Atualmente, a prática do cultivo consorciado é considerada uma das melhores alternativas para a sustentabilidade dos sistemas agrícolas tropicais (BORGHI et al., 2013), pois busca-se, com maior diversidade de espécies, melhorar o ambiente de produção pelas alterações provocadas nas características químicas, físicas e biológicas ao longo do tempo de adoção do sistema (GARCIA et al, 2008; CALONEGO et al., 2011).

Muitos agricultores têm realizado a semeadura de milho consorciado com forrageiras, com a intenção de formar maiores quantidades de material vegetal, seja para o pastejo após a colheita do milho segunda safra ou somente para formação de palhada para a semeadura direta (CRUSCIOL et al., 2009; KICHEL et al., 2009). As gramíneas utilizadas possuem grande potencial de melhoria das condições dos solos no cerrado, porém, sua utilização nem sempre é a mais indicada, visto que tanto o milho quanto o capim são multiplicadores de nematoides (NEVES et al., 2010; PINTO, 2008), sendo necessárias alternativas visando o cultivo da soja em sucessão.

Recentemente, tem-se constatado tentativas em se realizar o consórcio de milho (Zea mays) segunda safra com crotalárias, visando os múltiplos benefícios que a leguminosa pode proporcionar sem perder, porém, o retorno econômico promovido pelo milho na segunda safra.

A utilização desse tipo de consórcio, porém, tem sido realizada sem critérios técnicos bem definidos, visto que não há, na literatura, resultados que indiquem as melhores densidades populacionais a fim de se obter todos os benefícios do consórcio. Se, por um lado, a baixa densidade pode não proporcionar adequada cobertura do solo, para altas densidades, até o momento, não existem ferramentas que possibilitem a supressão de crescimento das crotalárias, como ocorre no consórcio com as gramíneas, devendo, o produtor, ficar atento a este fator, por ser um ponto chave do sucesso na consorciação de culturas.

O presente trabalho teve como objetivo avaliar o desempenho da soja (Glycine $\max (\mathrm{L}$.) Merrill) semeada em sucessão ao consórcio de milho (Zea mays L. spp) segunda safra com diferentes densidades de Crotalaria spectabilis.

\section{MATERIAL E MÉTODOS}

O trabalho foi conduzido na área experimental da Embrapa Agrossilvipastoril, no município de Sinop/MT, sob as coordenadas $11^{\circ} 51^{\prime} 27^{\prime \prime S}$ e $55^{\circ} 36^{\prime} 15^{\prime}$ O. O clima da região segundo a classificação de Köppen \& Geiger, é do tipo Aw, tropical, com médias anuais de temperatura de $25^{\circ} \mathrm{C}$ e precipitação média anual de 1974 mm (MOTTA et al., 2013), com altitude de $370 \mathrm{~m}$. O solo da área foi identificado como um Latossolo Vermelho Amarelo, com as seguintes características químicas: $\mathrm{pHCaCl}_{2}=6, \mathrm{M} . \mathrm{O} .=4,4 \mathrm{dag} \mathrm{kg}^{-1}$; PMelich $^{1}=5,4 \mathrm{mg} \mathrm{dm}^{-3} ; \mathrm{K}=33 \mathrm{mg} / \mathrm{dm}^{-3} ; \mathrm{Ca}=5,71 \mathrm{cmolc}$ $/ \mathrm{dm}^{-3} ; \mathrm{Mg}=1,02 \mathrm{cmolc} / \mathrm{dm}^{-3} ; \mathrm{Al}+\mathrm{H}=5,3 \mathrm{cmolc} / \mathrm{dm}^{-3} ; \mathrm{V}=$ $56 \%$; Argila $=563 \mathrm{~g} \mathrm{~kg}^{-1}$; Silte $=187 \mathrm{~g} \mathrm{~kg}^{-1}$; Areia $=251 \mathrm{~g} \mathrm{~kg}^{-}$ 1.

O delineamento do experimento foi o de blocos casualizados, com 4 repetições. Cada parcela experimental apresentava 11 linhas, espaçadas de $0,45 \mathrm{~m}$ entre si, e 11 metros de comprimento, perfazendo 49,5 m2. Considerou-se, como área útil, as três linhas centrais, desprezando-se $0,5 \mathrm{~m}$ de cada extremidade, totalizando-se $13,5 \mathrm{~m}^{2}$. 


\subsection{Tratamentos de outono-inverno}

Os tratamentos foram constituídos por 4 densidades de $C$. spectabilis, semeadas a lanço, sendo de 10, 20, 30 e $40 \mathrm{~kg}$ de sementes/ha em consórcio com Z. mays, além da testemunha com milho solteiro.

A semeadura do milho foi realizada em 15 de fevereiro de 2016, utilizando-se o híbrido DKB 175, de ciclo precoce, adicionando-se $350 \mathrm{~kg} \mathrm{ha}^{-1}$ do fertilizante com formulação 8:28:16 (N-P-K) no sulco de semeadura.

Realizou-se a aplicação, em cobertura, de $100 \mathrm{~kg} \mathrm{ha}^{-1}$ de N na forma de ureia, a lanço quando as plantas de milho apresentavam quatro folhas desenvolvidas. O controle de plantas daninhas foi efetuado totalmente em pré-emergência das plantas, utilizando-se 1440 g i.a. ha ${ }^{-1}$ do herbicida Smetolacloro $960 \mathrm{~g} \mathrm{~L}^{-1}$. Não houve necessidade de controle de plantas daninhas em pós-emergência, bem como controle para limitar o crescimento da crotalária. A colheita foi realizada em 15 de junho de 2016, utilizando-se colhedora de parcelas automotriz, de forma convencional, ou seja, sem dessecação das crotalárias cultivadas em consórcio. Momentos antes da colheita fez-se a avaliação do estande final de plantas de milho, bem como da densidade final de plantas de crotalária pela contagem de plantas por metro quadrado. $\mathrm{O}$ estante final de plantas de milho (POP), obtido através da contagem das plantas presentes nos 10 metros das duas linhas centrais, correspondendo à área útil de cada parcela; densidade final de plantas de crotalária - obtido através da contagem das plantas dentro de $0,5 \mathrm{~m}^{2}$ de cada parcela, sendo o resultado transformado para plantas $\mathrm{m}^{-2}$

Para avaliação dos componentes de rendimento, foram coletadas 10 plantas da área útil de cada parcela, onde foram avaliados em laboratório, os seguintes componentes produtivos: Massa média da espiga sem palha(ME) determinada através da relação entre a massa total das espigas e o número de espigas; Massa Média de grãos por espiga (GPE) - Depois de trilhados, o peso dos grãos foi determinado em balança de precisão, fazendo a relação entre o peso total dos grãos e o número de espigas; Número Médio de fileiras (FPE) - Determinado por meio do corte da espiga ao meio e posterior contagem do número de fileiras; Número Médio de grãos por fileira (GPF) - Determinado por meio da relação entre o número de grãos e o número de fileiras por espiga; Massa Média de 100 grãos (M100): determinada por meio da contagem de duas repetições de 100 grãos coletados ao acaso por parcela experimental e posterior pesagem em balança de precisão. A produtividade de grãos (PD) foi avaliada pela pesagem dos grãos colhidos na área útil, de $13,5 \mathrm{~m}^{2}$, sendo o resultado transformado em $\mathrm{kg} \mathrm{ha}^{-1}$ a $13 \%$ de umidade.

\subsection{Soja em sucessão aos tratamentos de outono-inverno}

No mês de outubro de 2016 realizou-se, sob as parcelas colhidas do consórcio, a semeadura da soja cultivar $M$ 8210IPRO, em semeadura direta, sob os restos culturais do cultivo antecessor, movimentando minimamente o solo pelos discos da semeadora. As sementes de soja foram inoculadas no momento da semeadura com Bradirhizobium japonicum. Aplicou-se, no sulco de semeadura, o equivalente a $400 \mathrm{~kg}$ ha ${ }^{1}$ do fertilizante 0:18:18 (NPK), de acordo com os resultados da análise de solo. A dessecação foi realizada 8 dias antes da semeadura da soja. utilizando-se 1.800 g e.a. ha ${ }^{-1}$ do herbicida glifosato. Nesse momento, as plantas remanescentes de crotalária estavam em fase de senescência. Vinte dias após a emergência da cultura, aplicou-se $1.080 \mathrm{~g}$ e.a. ha $^{-1}$ do herbicida quando as plantas daninhas apresentavam duas folhas completamente desenvolvidas, para a manutenção da cultura no limpo. O uso de inseticidas foi realizado sempre que atingiu nível de dano econômico, segundo EMBRAPA (2014). O controle de doenças foi realizado por meio da aplicação de fungicidas, sempre de forma preventiva, iniciando-se no préflorescimento, repetindo-se a cada 15 dias, totalizando-se 3 aplicações. A primeira aplicação utilizou-se o fungicida azoxistrobina $200 \mathrm{~g}$ i.a. $\mathrm{L}^{-1}+$ ciproconazol $80 \mathrm{~g} \mathrm{~L}^{-1}$, na dose de $0,3 \mathrm{~L}$ do produto comercial por hectare, a segunda aplicação utilizou-se o fungicida trifloxistrobina $150 \mathrm{~g}$ i.a. $\mathrm{L}^{-1}+$ protioconazol $175 \mathrm{~g}$ i.a. $\mathrm{L}^{-1}$, na dose de $0,4 \mathrm{~L}$ do produto comercial por hectare e, na terceira aplicação, utilizou-se o fungicida azoxistrobina $200 \mathrm{~g}$ i.a. $\mathrm{L}^{-1}+$ ciproconazol $80 \mathrm{~g} \mathrm{~L}^{-1}$, na dose de $0,3 \mathrm{~L}$ do produto comercial por hectare.

Na maturação da soja, para a avalição dos componentes do rendimento, foram coletadas 10 plantas, na área útil de cada parcela, momentos antes da colheita, para posterior avaliação em laboratório. A população de plantas foi avaliada pela contagem das plantas da parcela útil, transformando-se para plantas por hectare. Para altura de plantas, mediu-se o comprimento das plantas, do colo a parte mais alta, dividindose pelo número de plantas avaliado. $\mathrm{O}$ número de vagens por planta (NVP) foi obtido pela contagem do número de vagens em cada uma das 10 plantas, efetuando-se, posteriormente, a média para cada parcela experimental. $\mathrm{O}$ número de grãos por vagem (GPV), realizado pela contagem total de grãos das 10 plantas avaliadas, dividindo-se pelo número médio de vagens. A Massa de 100 grãos, obtida pela pesagem de 100 grãos de cada parcela, ajustando-se os dados para $13 \%$ de umidade. A produtividade de grãos (PROD), obtida pela pesagem de cada parcela útil, tendo sua umidade ajustada para $13 \%$.

\subsection{Análise dos dados}

Os dados foram submetidos à análise de variância. As médias dos fatores qualitativos foram comparados pelo teste de Scott Knott a 5\% de probabilidade e os fatores quantitativos foram ajustados a um modelo de regressão.

\section{RESULTADOS}

As variáveis analisadas (população final de plantas de milho por hectare, massa de 100 grãos, massa da espiga, massa de grãos por espiga, número de fileiras por espiga, número de grãos por fileira e produtividade) não foram influenciadas pela densidade de semeadura de crotalária (Tabela 1).

Tabela 1. Componentes do rendimento e produtividade de grãos de milho, em função de densidades de Crotalaria spectabilis cultivadas em consórcio. Sinop (MT), 2016

Table 1. Yield componentes and grain productivity of maize as a function of Crotalaria spectabilis densities grown in intercropping. Sinop (MT), 2016.

\begin{tabular}{cccccccc}
\hline $\begin{array}{l}\text { TRAT } \\
\mathrm{Kg} \mathrm{ha}^{-1}\end{array}$ & $\begin{array}{c}\text { POP } \\
\mathrm{n}^{\mathrm{o}} \mathrm{ha}^{-1}\end{array}$ & $\begin{array}{c}\mathrm{M} 100 \\
(\mathrm{~g})\end{array}$ & $\begin{array}{c}\mathrm{ME} \\
(\mathrm{g})\end{array}$ & $\begin{array}{c}\text { GPE } \\
(\mathrm{g})\end{array}$ & $\begin{array}{c}\text { FPE } \\
-\end{array}$ & $\begin{array}{c}\text { GPF } \\
-\end{array}$ & $\begin{array}{c}\mathrm{PD} \\
\mathrm{Kg} \mathrm{ha}^{-1}\end{array}$ \\
\hline 0 & 79166 & 34,4 & 197,9 & 168,4 & 16,1 & 32,1 & 7562 \\
10 & 86666 & 34,2 & 187,0 & 158,5 & 15,9 & 32 & 7196 \\
20 & 79444 & 33,9 & 190,2 & 161,4 & 15,2 & 32,2 & 6819 \\
30 & 83888 & 29,7 & 173,1 & 145,9 & 15,7 & 33,1 & 6191 \\
40 & 85555 & 32,3 & 183,0 & 154,6 & 15,8 & 32,1 & 7662 \\
Média & 82943 & 32,9 & 186,2 & 157,8 & 15,7 & 32,3 & 7086 \\
f calc & $1,5^{\text {ns }}$ & $1,9^{\text {ns }}$ & $0,69^{\text {ns }}$ & $0,71^{\text {ns }}$ & $0,75^{\text {ns }}$ & $0,24^{\text {ns }}$ & $1,6^{\text {ns }}$ \\
\hline CV $(\%)$ & 6,82 & 8,71 & 11,8 & 12,54 & 4,75 & 5,6 & 13,27 \\
\hline
\end{tabular}

ns = não significativo pelo teste de Scott Knott a 5\% de probabilidade. ns $=$ not significant by the Scott Knott test at $5 \%$ probability. 
Em relação ao número de fileiras de grãos por espiga, observou-se valor médio de 15,7 com média de 32,3 grãos por fileira, bem como valor médio de $32,9 \mathrm{~g}$ para a massa de 100 grãos e produtividade média de $7086 \mathrm{~kg} \mathrm{ha}^{-1}$.

Para a massa de grãos por espiga, os resultados não apresentaram diferenças significativas entre os tratamentos, tendo-se obtido média de 157,8 g. No entanto, os valores de produtividade se mostraram semelhantes, com média de 7100 $\mathrm{kg} \mathrm{ha}^{-1}$.

Observa-se que não houve diferença entre as produtividades nas diferentes densidades de crotalária. A produtividade média constatada no presente trabalho foi de $7086 \mathrm{~kg} \mathrm{ha}^{-1}$ mostrando-se superior a média brasileira e do estado de Mato Grosso, que foi de $5347 \mathrm{~kg} \mathrm{ha}^{-1}$ e $5679 \mathrm{~kg}$ ha ${ }^{1}$, respectivamente nas safras 2016 e 2017 (CONAB, 2017).

A população final de plantas de crotalária em função das densidades de semeadura encontra-se na Figura 1. Os resultados mostram que houve aumento linear no número de plantas por metro quadrado em razão das diferentes densidades semeadas no consórcio. Observa-se que mesmo na maior densidade avaliada, não houve competição da leguminosa utilizada com o milho.

Pelo fato de, neste ano agrícola, ter ocorrido forte influência do fenômeno "el ninho", as chuvas cessaram antecipadamente. O déficit hídrico ocasionado, limitando a sobrevivência das crotalárias na área, no momento da colheita, tornou a coleta da leguminosa pouco representativa para a avaliação da palhada. A Crotalaria spectabilis, por ter porte relativamente baixo, não comprometeu a colheita, nem houve necessidade de se reduzir a velocidade da mesma, facilitando a implementação da tecnologia em áreas comerciais.

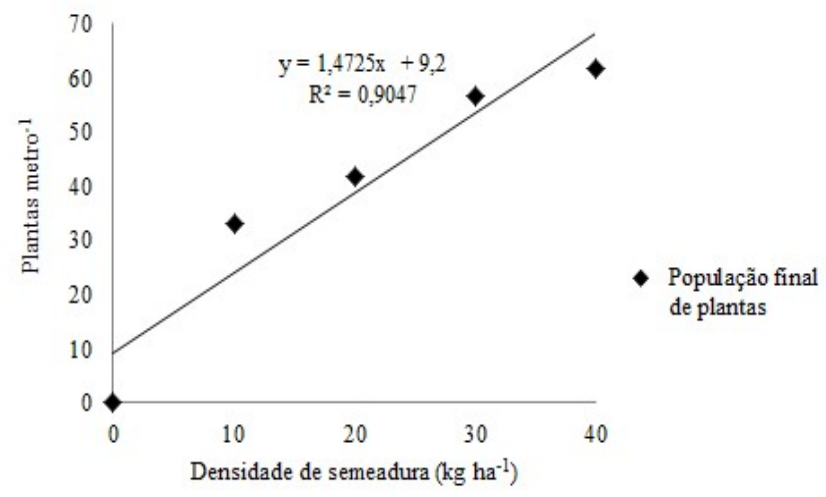

Figura 1. População final de plantas de Crotalaria spectabilis em função das densidades de semeadura. Sinop-MT, 2016.

Figure 1. Final population of Crotalaria spectabilis plants as a function of seeding densities. Sinop-MT, 2016.

Dentre os componentes de produção de soja avaliados (Tabela 2) nenhum deles diferiu entre os tratamentos, exceto para a população de plantas. Quanto a população de plantas, observou-se diferenças na população, somente onde anteriormente havia os tratamentos nas doses de 30 e $40 \mathrm{~kg}$ ha ${ }^{1}$ de sementes de $C$. spectabilis. A dose de $30 \mathrm{~kg} \mathrm{ha}^{-1}$ foi a que apresentou a maior população final de plantas, seguida pela sucessão ao tratamento com $40 \mathrm{~kg} \mathrm{ha}^{-1}$, diferindo-se das demais. Apesar das diferenças observadas entre os tratamentos, não foi possível identificar diferenças nos demais componentes e na produtividade de grãos.
Tabela 2. Componentes do rendimento e produtividade de grãos de soja cultivados em sucessão ao milho segunda safra consorciado com diferentes densidades de Crotalaria spectabilis. Sinop (MT), 2017.

Table 2. Yield componentes and grain productivity of soybeans grown in succession to second crop maize intercropping with different densities of Crotalaria spectabilis. Sinop (MT), 2017.

\begin{tabular}{ccccccc}
\hline $\begin{array}{c}\text { TRAT } \\
\text { Kg.ha }^{-1}\end{array}$ & $\begin{array}{c}\text { POP } \\
\text { pl.ha }^{-1}\end{array}$ & $\begin{array}{c}\text { ALT } \\
(\mathrm{m})\end{array}$ & $\begin{array}{c}\text { NVP } \\
\left(\mathrm{n}^{\mathrm{o}}\right)\end{array}$ & $\begin{array}{c}\text { GPV } \\
\left(\mathrm{n}^{\mathrm{o}}\right)\end{array}$ & $\begin{array}{c}\text { M100 } \\
(\mathrm{g})\end{array}$ & $\begin{array}{c}\text { PROD } \\
\text { Kgha }^{-1}\end{array}$ \\
\hline 0 & $186109 \mathrm{c}$ & 0,57 & 47 & 2,1 & 16,7 & 4150 \\
10 & $197220 \mathrm{c}$ & 0,60 & 59 & 2,0 & 16,9 & 4348 \\
20 & $196664 \mathrm{c}$ & 0,58 & 55 & 2,2 & 16,9 & 4394 \\
30 & $263886 \mathrm{a}$ & 0,60 & 53 & 2,1 & 16,8 & 4003 \\
40 & $236108 \mathrm{~b}$ & 0,57 & 60 & 1,9 & 15,6 & 3988 \\
\hline Média & 215997 & 58,3 & 54,6 & 2,0 & 16,6 & 4177 \\
F calc & $13,68^{*}$ & $0,63^{\text {ns }}$ & $1,26^{\text {ns }}$ & $2,70^{\text {ns }}$ & $2,90^{\text {ns }}$ & $1,06^{\text {ns }}$ \\
CV $(\%)$ & 8,23 & 7,40 & 16,61 & 7,32 & 4,01 & 8,80
\end{tabular}

Tabela 2. TRAT $=$ tratamentos, $\mathrm{POP}=$ população final de plantas de soja por hectare, $\mathrm{ALT}=$ altura de plantas, $\mathrm{NVP}=$ número de vagens por planta, $\mathrm{GPV}=$ número de grãos por vagem, $\mathrm{M} 100=$ massa de 100 grãos, $\mathrm{PROD}=$ produtividade e ns $=$ não significativo pelo teste Tukey a $5 \%$ de probabilidade. Table 2. TRAT $=$ treatments, $\mathrm{POP}=$ final soybean plant population per hectare, $\mathrm{ALT}=$ plants height, $\mathrm{NVP}=$ number of pods per plant, $\mathrm{GPV}=$ number of grains per pod, $\mathrm{M} 100=100$ grain mass, $\mathrm{PROD}=$ productivity and $\mathrm{ns}=$ not significant by the Tukey test at $5 \%$ probability.

\section{DISCUSSÃO}

Os resultados foram semelhantes aos verificados por Perin et al., 2007; Cortez et al., 2009; Madalon et al., 2016; Santos et al., 2016. Estes, ao avaliarem o comportamento da cultura do milho em sistemas consorciados, não verificaram diferença significativa para estas variáveis. A ausência de influência dos adubos verdes sobre a cultura do milho pode estar relacionada ao fato desta cultura ser ótima competidora, devido, principalmente, à sua maior taxa de acúmulo de matéria seca produzida nos estádios iniciais de desenvolvimento (SILVA et al., 2004). Além de apresentar elevada capacidade de interceptação da radiação, fotossinteticamente ativa ao longo de seu dossel, o que reduz a quantidade desse recurso para as outras espécies em consórcio (FREITAS et al., 2008). Tal resultado é satisfatório do ponto de vista agronômico, devido à necessidade de se buscar alternativas para avanço do sistema produtivo; com aporte de palha, de $\mathrm{N}$ e redução de nematoides.

Zucareli et al. (2016), observaram em seu trabalho sobre desempenho de híbridos de milho, que as melhores performances apresentaram número de fileiras de grãos igual a 18 , com 30 grãos por fileira e massa de 100 grãos igual a $33,2 \mathrm{~g}$, apresentando produtividade de $6.950 \mathrm{~kg} / \mathrm{ha}$, valores próximos dos observados no presente trabalho. Já Araújo et al. (2016), ao avaliarem o desempenho de híbridos de milho precoce no estado de Goiás, observaram no número de fileiras por espiga um valor médio de 18 , bem como uma quantidade de grãos por fileira igual a 32 , apresentado uma produtividade de $8.016 \mathrm{~kg} \mathrm{ha}^{-1}$; valores superiores ao presente estudo, porém, sob condições climáticas e genéticas diferentes. Pereira et al. (2011) também não observaram diferenças entre o consórcio de milho e Crotalaria juncea, em relação ao milho solteiro, em apenas um ciclo de cultivo.

Ferreira et al. (2010), observaram que o valor máximo de massa da espiga, em função de doses de $\mathrm{N}$, foi obtido com a aplicação de $150 \mathrm{~kg} \mathrm{ha}^{-1}$ de $\mathrm{N}$, correspondendo a $184 \mathrm{~g}$ por espiga, sendo próximo do resultado médio obtido no presente trabalho, que foi de 186,2 g. De maneira geral, na ausência de condições adversas, o arranjo de plantas no consórcio, aliado a uma boa nutrição pode promover a formação de espigas 
maiores e, consequentemente, com maior massa (BORGHI et al., 2004). Gonçalves et al. (2016) observaram no consócio de milho com Urochloa ruziziensis um valor médio de espigas de $175 \mathrm{~g}$, superior ao valor observado no presente estudo. No entanto, os valores de produtividade se mostraram semelhantes, com média de $7100 \mathrm{~kg} \mathrm{ha}^{-1}$, mostrando a influência da cultivar e do clima nas alterações dos componentes produtivos, que muitas vezes não influenciam na produtividade final.

A $C$. spectabilis semeada na segunda safra, não forma quantidades abundantes de sementes, devido ao déficit hídrico a partir de abril, sendo benéfico para a colheita do milho segunda safra. É preciso ressaltar a alta pluviosidade, associado a altas temperaturas, ocorrida no período de condução da cultura da soja, que favoreceu a rápida decomposição da palhada remanescente de crotalária, e, por conseguinte, os nutrientes contidos nela. Boer et al. (2007), avaliaram a ciclagem de nutrientes no Cerrado empregando plantas de cobertura semeadas na safrinha e concluíram que a maioria dos nutrientes é liberada de forma precoce para aproveitamento da safra seguinte em razão da rápida decomposição dos resíduos vegetais. Desta forma a liberação de nutrientes da cultura antecessora pode não influenciar na produtividade da soja. Com isso, se faz necessário o estudo de técnicas que elevem o acúmulo de fitomassa por parte das plantas de cobertura (KLIEMANN et al., 2006) e que sincronizem a decomposição da palhada e a taxa de liberação dos nutrientes com a necessidade das culturas anuais semeadas em sucessão (GAMA-RODRIGUES et al., 2007). Segundo Pereira et al. (2011), cultivos consorciados tendem a apresentar melhores resultados, pois o cultivo em ciclos sucessivos pode ocasionar maior acúmulo de matéria orgânica e de nutrientes no solo, o que é obtido com o decorrer do tempo.

A continuidade do trabalho por mais de um ciclo de sucessão deve ser realizada visando-se obter incrementos na produtividade de grãos de soja e avaliar quais densidades de semeadura de crotalária são as mais indicadas para o sistema produtivo. Estudos de maior duração podem possibilitar melhor caracterização dos benefícios que a palhada de plantas de cobertura podem trazer para o sistema produtivo, como a redução das perdas por erosão, ciclagem de nutrientes e aumento da população microbiana. Os resultados alcançados no presente estudo demonstram a viabilidade de se realizar o consórcio do milho segunda safra com a crotalária, sem que ocorra perdas de rendimento na cultura de interesse econômico.

\section{CONCLUSÕES}

O desempenho da soja semeada em sucessão não foi influenciado pelo consórcio de milho segunda safra com diferentes densidades de Crotalaria spectabilis.

Não houve redução na produtividade de milho segunda safra para nenhuma das densidades de consórcio com Crotalaria spectabilis, demonstrando potencial para a sua utilização.

\section{REFERÊNCIAS}

ANDREOLA, F.; COSTA, L. M.; OLSZEVSKI, N.; JUCKSCH, I. A cobertura vegetal de inverno e a adubação orgânica e, ou, mineral influenciando a sucessão feijão/ milho. Revista Brasileira de Ciência do Solo, Viçosa, v.
24, n. 4, p. 867-874, 2000. DOI: http://dx.doi.org/10.1590/S0100-06832000000400018

ARAÚJO, L. S.; SILVA, L. G. B.; SILVEIRA, P. M.; RODRIGUES, F.; LIMA, M. L. P.; CINHA, P. C. R. Desempenho agronômico de híbridos de milho na região sudeste de Goiás. Revista Agroambiente On-line, Boa Vista, v. 10, n. 4, p. 334-341, outubro-dezembro, 2016. DOI: $\quad$ http://dx.doi.org/10.18227/19828470ragro.v10i4.3334

BOER, C. A.; ASSIS, R. L.; SILVA, G. P.; BRAZ, A. J. B. P.; BARROSO, A. L. L.; CARGNELUTTI FILHO, A.; PIRES, F. R. Ciclagem de nutrientes por plantas de cobertura na entressafra em um solo de cerrado. Pesquisa Agropecuária Brasileira, Brasília, v. 42, p. 1269-1276, 2007. DOI: http://dx.doi.org/10.1590/S0100204X2007000900008

BONFIM-SILVA, E. M.; VALADÃO JÚNIOR, D. D.; REIS, R. H. P. dos; CAMPOS, J. J.; SCARAMUZZA, W. L. M. P. Establishment of Xaraés and Marandu grasses under levels of soil compaction. Revista Engenharia Agrícola, Jaboticabal, v. 32, n. 4, p. 727-735, 2012. DOI: http://dx.doi.org/10.1590/S0100-69162012000400012

BORGHI, E.; CRUSCIOL, C. A. C.; MATEUS, G. P.; NASCENTE, A. S.; MARTINS, P. O. Intercropping time of corn and palisadegrass or guineagrass affecting grain yield and forage production. Crop Science, Madison, v. 53, p. 629-636, 2013. DOI: http://dx.doi.org/10.2135/cropsci2012.08.0469

BORGHI, E.; MELlO, L. M. M.; CRUSCIOL, C. A. C. Adubação por área e por planta, densidade populacional e desenvolvimento do milho em função do sistema de manejo do solo. Acta Scientiarum, Maringá, v. 26, n. 3, p. 337-345, 2004.

CALEGARI, A. Perspectivas e estratégias para a sustentabilidade e o aumento da biodiversidade dos sistemas agrícolas com o uso de adubos verdes. In: LIMA FILHO, O. F. de; AMBROSANO, E. J.; ROSSI, F.; CARLOS, J. A. D. Adubação verde e plantas de cobertura no Brasil: fundamentos e prática. Brasília: Embrapa, 2014. 1 v. 507 p.

CAlOneGO, J. C.; BORGHi, E.; CRUSCIOL, C. A. C. Intervalo hídrico ótimo e compactação do solo com cultivo consorciado de milho e braquiária. Revista Brasileira de Ciência do Solo, Viçosa, v. 35, n. 6, p. 2183-2190, 2011. http://dx.doi.org/10.1590/S0100-06832011000600033

CONAB_COMPANHIA NACIONAL DE ABASTECIMENTO. Acompanhamento de safra brasileira: grãos, quinto levantamento, abril/2017. Brasília: CONAB, 2017.157p. Disponível em: https://www.conab.gov.br/info-agro/safras/graos/boletimda-safra-degraos/item/download/1312_085724fefaa1fbc7c26c50855f be61b4. Acesso em: 19/08/2019.

CORTEZ, J. W.; FURLANI, C. E. A.; SILVA, R. P. Sistemas de adubação e consórcio de culturas intercalares e seus efeitos nas variáveis de colheita da cultura do milho. Engenharia Agrícola, Jaboticabal, v. 29, n. 2, p. 277-287, 2009. DOI: http://dx.doi.org/10.1590/S010069162009000200011

COSTA, N. R.; ANDREOTTI, M.; ULIAN, N. de A.; COSTA, B. S.; PARIZ, C. M.; TEIXEIRA FILHO, M. C. M. Acúmulo de nutrientes e tempo de decomposição da palhada de espécies forrageiras em função de épocas de 
semeadura. Bioscience Journal, Uberlândia, v. 31, n. 3, p. 818-829, 2015. DOI: https://doi.org/10.14393/BJv31n3a2015-22434

CRUSCIOL, C. A. C.; SORATTO, R. P.; BORGHI, E.; MATEUS, G. P. Integração Lavoura-Pecuária: Benefício das gramíneas perenes nos sistemas de produção. Informações Agronômicas, Piracicaba, n. 125, p. 2-15, 2009.

DOURADO, M. C.; SILVA, T. R. B.; BOLONHEZI, A. C. Matéria seca e produção de grãos de Crotalaria juncea $\mathrm{L}$. submetida à poda e adubação fosfatada. Scientia Agrícola, Piracicaba, v. 58, n. 2, p. 287-293, 2001. DOI: http://dx.doi.org/10.1590/S0103-90162001000200011

DUARTE, I. B.; GALO, A. S.; GOMES, M. S.; GUIMARAES, N. F.; ROCHA, D. P.; SILVA, R. F. Plantas de cobertura e seus efeitos na biomassa microbiana do solo. Acta Iguazu, Cascavel, v. 3, p. 150, 2014.

EMBRAPA_EMPRESA BRASILEIRA DE PESQUISA AGROPECUÁRIA. Tecnologias de produção de soja: região central do Brasil 2013. Londrina: Embrapa Soja. 2014. 265 p. (Sistemas de Produção, 16).

FERREIRA, H. A.; SOUZA, A. S.; SOUSA, D. A.; MARACAJÁ, P. B. Componentes de produção e produtividade do milho submetido a doses de nitrogênio no semiárido paraibano. Revista Verde, Mossoró, v. 5, n. 4, p. 90-96, 2010.

FINHOLDT, R. S.; ASSIS, A. M.; BISINOTTO, F. F.; AQUINO JÚNIOR, V. M.; SILVA, L. O. Avaliação da biomassa e cobertura do solo de adubos verdes. FAZU em Revista, Uberaba, n. 6, p. 11-14, 2009.

FREITAS, F. C. L.; SANTOS, M. V.; MACHADO, A. F. L.; FERREIRA, L. R.; FREITAS, M. A. M.; SILVA, M. G. O. Comportamento de cultivares de milho no consórcio com Brachiaria brizantha na presença e ausência de foramsulfuron+iodosulfuron-methyl para 0 manejo da forrageira. Planta Daninha, Viçosa, v. 26, n. 4, p. 215221, 2008. DOI: http://dx.doi.org/10.1590/S010083582008000100022

GAMA-RODRIGUES, A. C.; GAMA-RODRIGUES, E. F.; BRITO, E. C. Decomposição e liberação de nutrientes de resíduos culturais de plantas de cobertura em Argissolo Vermelho-Amarelo na região Noroeste Fluminense (RJ). Revista Brasileira de Ciência do Solo, Viçosa, v. 31, n. 6, p. 1421- 1428, 2007. http://dx.doi.org/10.1590/S010006832007000600019

GARCIA, R. A.; CRUSCIOL, C. A. C ; CALONEGO, J. C.; ROSOLEM, C. A. Potassium cycling in a corn-brachiaria cropping system. European Journal of Agronomy, v. 28, n. $4, \quad$ p. $\quad 579-585, \quad 2008$. https://doi.org/10.1016/j.eja.2008.01.002

GONÇALVES, A. K. A.; SILVA, T. R. B.; BRANDÃO, A. G. Manejo de adubação nitrogenada em milho solteiro e em consorciado com Brachiaria ruziziensis. Revista Brasileira de Milho e Sorgo, Sete Lagoas, v. 15, n. 2, p. 318-327, 2016. http://dx.doi.org/10.18512/19806477/rbms.v15n2p318-327

KERMAH, M.; FRANKE, A. C.; ADJEI-NSIAH, S.; AHIABOR, B. D. K.; ABAIDOO, R. C.; GILLER, K. E. Maize-grain legume intercropping for enhanced resource use efficiency and crop productivity in the Guinea savanna of northern Ghana. Field Crops Research, Amsterdam, v. 213, p. 38-50, 2017. DOI: https://dx.doi.org/10.1016/j.fcr.2017.07.008
KICHEL, A. N.; COSTA, J. A. A.; ALMEIDA, R. G. de. Cultivo simultâneo de capins com milho safrinha: produção de grãos, de forragem e de palhada para plantio direto. Campo Grande: Embrapa Gado de Corte, 2009. 24 p. (Documentos, 177).

KLIEMANN, H. J.; BRAZ, A. J. B. P.; SILVEIRA, P. M. Taxas de decomposição de resíduos de espécies de cobertura em Latossolo Vermelho Distroférrico. Pesquisa Agropecuária Tropical, Goiânia, v. 36, p. 21- 28, 2006.

LÁZARO, R. de L.; COSTA, A. C. T. da; SILVA, K. de F. da; SARTO, M. V. M.; DUARTE JÚNIOR, J. B. Produtividade de milho cultivado em sucessão à adubação verde. Pesquisa Agropecuária Tropical, Goiânia, v. 43, n. $1, \quad$ p. $10-17, \quad 2013 . \quad$ DOI: http://dx.doi.org/10.1590/S1983-40632013000100008

MACEDO, M. C. M. Integração lavoura e pecuária: o estado da arte e inovações tecnológicas. Revista Brasileira de Zootecnia, Viçosa, v. 38, n. 1, p. 133-146, 2009. DOI: http://dx.doi.org/10.1590/S1516-35982009001300015

MADALON, F. Z.; MENEGHELLI, C. M.; SCHMIDT, J.; DALEPRANE, F. B.; PREZOTTI, L. Influência do consórcio de feijão-de-porco (Canavalia ensiformis L.) cultivado em diferentes arranjos espaciais sobre a produção de milho. Cadernos de Agroecologia, Pernambuco, v. 10, n. 3, p. 1-5, 2016.

MATEUS, G. P.; WUTKE, E. B. Espécies de leguminosas utilizadas como adubos verdes. Pesquisa \& Tecnologia, v. 8, n. 103, 2011.

MENDONÇA, V. Z.; MELLO, L. M. M.; ANDREOTTI, M.; PEREIRA, F. C. B. L.; LIMA, R. C.; VALÉRIO FILHO, W. V.; YANO, E. H. Avaliação dos atributos físicos do solo em consórcio de forrageiras, milho em sucessão com soja em região de cerrados. Revista Brasileira de Ciência do Solo, Viçosa, v. 37, n. 1, p 251-259, 2013. DOI: http://dx.doi.org/10.1590/S0100-06832013000100026

MHLANGA, B.; CHEESMAN, S.; MAASDORP, B.; MUPANGWA, W.; MUNYORO, C.; SITHOLE, C.; THIERFELDEER, C. Effects of relay cover crop planting date on their biomass and maize productivity in a subhumid region of Zimbabwe under conservation agriculture. NJAS - Wageningen Journal of Life Sciences, Amsterdam, v. 78, p. 93-101, 2016. DOI: https://dx.doi.org/10.1016/j.njas.2016.05.001

NEVES, W. S.; PARRELLA, N. N. L. D.; PARREIRA, D. F. Nematoides que atacam a cultura do milho. Viçosa: Virtual Gráfica, 2010. $6 \mathrm{p}$.

PANDEY, R. K.; PENDLETON, J. W. Soybeans as green manure in a maize intercropping system. Experimental Agriculture, Cambridge, v. 22, n. 2, p. 179-185, 1986. DOI: https://dx.doi.org/10.1017/S0014479700014253

PEREIRA, L. C.; FONTANETTI, A.; BATISTA, J. N.; GALVÃO, J. C. C.; GOULART, P. L. Comportamento de cultivares de milho consorciados com Crotalaria juncea: estudo preliminar. Revista Brasileira de Agroecologia, v. 6, n. 3, p. 191-200, 2011.

PERIN, A.; BERNARDO, J. T.; SANTOS, R. H. S.; FREITAS, G. B. Desempenho agronômico de milho consorciado com feijão-de-porco em duas épocas de cultivo no sistema orgânico de produção. Ciência e Agrotecnologia, Lavras, v. 31, n. 3, p. 903-908. DOI: http://dx.doi.org/10.1590/S1413-70542007000300043

PINTO, N. F. J. de A. Doenças: doenças causadas por nematóides. In: CRUZ, J. C. (Ed.). Cultivo do milho. 4. 
ed. Sete Lagoas: Embrapa Milho e Sorgo, 2008. (Embrapa Milho e Sorgo. Sistemas de produção, 1).

RAMAKRISHNA, A.; ONG, C. K.; REDDY, L. N. Canopy duration and structure of pigeonpea intercropped with upland rice. Experimental Agriculture, Cambridge, v. 28, n. 3, p. 295-307, 1992. DOI: https://dx.doi.org/10.1017/S001447970001989X

REINERT, D. J.; ALBUQUERQUE, J. A.; REICHERT, J. M.; AITA, C.; ANDRADA, M. M. C. Limites críticos de densidade do solo para o crescimento de raízes de plantas de cobertura em argissolo vermelho. Revista Brasileira de Ciência do Solo, Viçosa, MG, v. 32, n. 5, p. 1805-1816, 2008. Separata de Revista Brasileira de Ciência do Solo, Viçosa, v. 32, n. 5, 2008. DOI: http://dx.doi.org/10.1590/S0100-06832008000500002

SANTOS, M. A.; BATISTA, P. S. C.; LOPES, M. F.; SILVA, M. G. M.; BERTO, A. L. F. Desempenho agronômico de milho consorciado com feijão-de-corda em diferentes populações e arranjos de plantas no semiárido mineiro. Revista Agro@mbiente, Boa Vista, v. 10, n. 3, p. 201-208. DOI: http://dx.doi.org/10.18227/19828470ragro.v10i3.3286

SILVA, A. A.; JAKELAITIS, A.; FERREIRA, L. R. Manejo de plantas daninhas no sistema integrado agriculturapecuária. In: Zambolim, L.; Ferreira, A.A. \& Agnes, E.L. (Ed.) Manejo integrado: integração agriculturapecuária. Viçosa: Universidade Federal de Viçosa, 2004. p. $117-169$
SOUZA, A. P.; MOTA, L. L.; ZAMADEI, T.; MARTIN, C. C.; ALMEIDA, F. T.; PAULINO, J. Classificação climática e balanço hídrico climatológico no esado de Mato Grosso. Nativa, v. 1, n. 1, p. 38-44, 2013. DOI: https://dx.doi.org/10.14583/2318-7670.v01n01a07

SOUZA, C. M.; PIRES, F. R. Adubação verde e rotação de culturas. Viçosa: UFV, 2002. 72 p.

TORRES, J. L. R.; PEREIRA, M. G.; ANDRIOLI, I.; POLIDORO, J. C.; FABIAN, A. J. Decomposição e liberação de nitrogênio de resíduos culturais de plantas de cobertura em um solo de cerrado. Revista Brasileira de Ciência do Solo, Viçosa, v. 29, n. 4, p. 609-618, 2005. DOI: http://dx.doi.org/10.1590/S010006832005000400013

YADAV, R. L. Intercropping pigeonpea to conserve fertilizer nitrogen in maize and produce residual effects on sugarcane. Experimental Agriculture, Cambridge, v. 17, n. $3, \quad$ p. 311- 315, 1981 . https://dx.doi.org/10.1017/S0014479700011674

ZUCARELI, C.; OLIVEIRA, M. A.; SPOLAOR, L. T.; FERREIRA, A. S. Desempenho agronômico de genótipos de milho de segunda safra na região Norte do Paraná. Scientia Agraria Paranaensis, Cascavel, v. 12, n. 3, p. 227-235, 2016. DOI: http://dx.doi.org/10.18188/19831471/sap.v12n3p227-235 